who have evidence of ventricular dilatation in the computed tomogram. The procedure may produce sufficient improvement in the clinical grade to warrant operative intervention on the aneurysm. In the more usual form of hydrocephalus, communicating hydrocephalus, temporary external drainage may be achieved simply by using a spinal drain. Where direct ventricular drainage is used, it is useful to connect the catheter to an intracranial pressure transducer to establish that intracranial hypertension exists, and cerebrospinal fluid may then be drained through the transducer. A drainage level of about $25 \mathrm{~mm}$ $\mathrm{Hg}$ is generally used, though the level tends to be adjusted to one that provides optimal benefit to the patient.

Another putative problem with external drainage is that by diverting cerebrospinal fluid from the ventricles the subarachnoid pathways are less efficiently opened up and the debris of the subarachnoid haemorrhage is only cleared slowly, thus predisposing to an increased incidence of late shunt dependent hydrocephalus. There is little foundation for the belief that early surgery on patients with a subarachnoid haemorrhage may help to open up the pathways and prevent late hydrocephalus by washing blood clot out of the basal cisterns. Such aggressive evacuation of the basal cisterns may predispose to greater damage, ${ }^{26}$ and increase the risk of late hydrocephalus. ${ }^{27}$

Delayed presentations of hydrocephalus include a spectrum of signs and symptoms ranging through continuing headache, restlessness with neck stiffness, impaired conscious level, disorientation, dementia, incontinence, with apraxia of gait, which result in the patient becoming bedbound, akinetic, and mute. ${ }^{13}$ When the aetiology of the triad of disturbance of gait, incontinence, and dementiaHakim's normal or intermittently raised pressure hydrocephalus ${ }^{14}$ - is known (as it is after subarachnoid haemorrhage) insertion of a ventricular shunt gives good results in about $65 \%$ of patients and complete recovery in at least $30 \%$. ${ }^{\text {is }}$ If sequential computed tomographic studies show progressive ventricular enlargement and periventricular lucency, and this is associated with progressive neurological deterioration or failure to improve, a shunt is clearly indicated. In borderline cases the best predictive test for recovery with a shunt is monitoring the intracranial pressure for 24 to 48 hours and noting the mean and pulse pressures and pattern of wave activity. ${ }^{16} \mathrm{~A}$ permanent shunt should be avoided if possible, because of long term complications. ${ }^{15} 17$

Ventricular drainage of cerebrospinal fluid is now restricted to selective cases, and it is one example of the increasingly critical attitude being adopted to the management of patients with subarachnoid haemorrhage. Well controlled, large scale studies of risk factors and drug treatment are needed; these include age, hypertension, clinical grading, timing of surgery, antifibrinolytic treatment, antiplatelet drugs, calcium antagonists, preoperative hypotension to reduce rebleeding, and postoperative hypertension to combat cerebral ischaemia. The results of such studies, with the use of cerebrovascular reactivity tests and intraoperative monitoring of evoked potentials, should help the clinician to tailor his or her management to suit the individual patient. Such a flexible approach to treatment is essential, for blanket application of standard regimens has all too often been shown to do as much harm as good.

J D PICKARD

Consultant Neurosurgeon and

Reader in Neurosurgical Sciences,

Wessex Neurological Centre,

Southampton SO9 4XY
I Bartlett JR. Subarachnoid haemorrhage. Br Med J 1981;283:1347-8.

Hitchcock ER. Ruptured aneurysms. Br Med f 1983;286:1299-300.

Van Crevel $\mathrm{H}$. Pitfalls in the diagnosis of rebleeding from intracranial aneurysms. Clin Neurol Neurosurg 1980;82:1-9.

Kassell NF, Torner JC. Aneurysmal rebleeding: a preliminary report from the co-operative aneurysm study. Neurosurgery 1983;13:479-81.

ell BA, Kendall BE, Symon L. Computerized tomography in aneurysmal subarachnoid

haemorrhage. I Neurol Neurosurg Psychratry 1980;43:522-4.
Fisher CM, Kistler JB, Davis JM. Relation of cerebral vasospasm to subarachnoid hemorrhage.

列 Zierski J, Eds. Cerebral aneurysms. Berlin: Springer-Verlag, 1979:162-8.

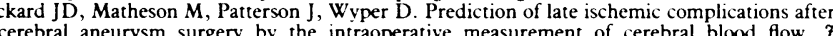
Neurosurg 1980;53:305-8.

Farrar JK, Gamache FW, Ferguson GG. Effects of profound hypotension on cerebral blood flow during surgery for intracranial aneurysms. I Neurosurg 1981;55:857-64

Doczi T, Nemessanyi Z, Szegvary Z, Huszka E. Disturbances of cerebrospinal fluid circulation during the acute stage of subarachnoid hemorrhage. Neurosurgery 1983;12:435-8.

Vassilouthis $\mathrm{J}$, Richardson $\mathrm{AE}$. Ventricular dilatation and communicating hydrocephalus following spontaneous subarachnoid hemorrhage. $\mathcal{J}$ Neurosurg 1979;51:341-51.

Kohi, YM, Johnston RA, Devkota UP. Acute obstructive hydrocephalus after subarachnoid haemorrhage. Br Med f 1984;288: 1342.

Foltz EL, Ward AA Jr. Communicating hydrocephalus from subarachnoid bleeding. $\mathcal{F}$ Neurosurg 1956;13:546-66.

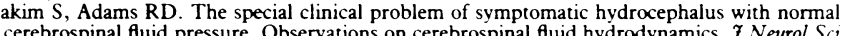
cerebrospinal fluir $1965 \cdot 2 \cdot 307-27$.

Pickard JD. Adult communicating hydrocephalus. Br f Hosp Med 1982;27:35-44

Symon L, Dorsch NWC, Stephens RJ. Pressure waves in so-called low pressure hydrocephalus. Lancet 1972;ii:1291-2.

${ }^{17}$ Simpson D. Living with hydrocephalus. Br Med 7 1984;288:813-4

${ }_{18}$ Kusske JA, Turner PT, Ojemann GA, Harris AB. Ventriculostomy for the treatment of acute hydrocephalus following subarachnoid hemorrhage. $\mathcal{F}$ Neurosurg 1973;38:591-5.

Menon D, Weir B, Overton T. Ventricular size and cerebral blood flow following subarachnoid hemorrhage. $\mathcal{f}$ Comput Assist Tomogr 1981;5:328-33

Mohr G, Ferguson G, Khan M, et al. Intraventricular hemorrhage from ruptured aneurysm. Retrospective analysis of 91 cases. $\mathcal{F}$ Neurosurg 1983;58:482-7.

McComb JG, Ramos AD, Platzker ACG, Henderson DJ, Segall HD. Management of hydrocephalus secondary to intraventricular hemorrhage in the preterm infant with a

Nornes $\mathrm{H}$. The role of intracranial pressure in the arrest of hemorrhage in patients with ruptured intracranial aneurysm. I Neurosurg 1973;39:226-34.

gren $\}$ Zwetnow NN. Kinetics of arterial and venous haemorrhage in the skull cavity. In: (1972:155-9.

undbarg G, Ponten U. ICP and CSF absorption impairment after subarachnoid haemorrhage. In: Beks JWW

Voldby B, Enevoldsen EM. Intracranial pressure changes following aneurysm rupture. Part 3. Recurrent hemorrhage. I Neurosurg 1982;56:784-9.

Yasui N, Ito Z, Ohta $\mathbf{H}$, Suzuki $\mathbf{A}$. Surgical problems and pathophysiology in severe cases with ruptured aneurysm in the acute stage. Acta Neurochir 1982;63:163-74.

Shigeno T, Aritake K, Saito I, Sano K. Hydrocephalus following early operation on ruptured cerebral aneurysms: significance of lorig-term monitoring of intracranial pressure. In: Shulman $\mathrm{K}$, Marmarou A, Miller JD, Becker DP, Hochwald GM, Brock M, eds. Intracranial pressure $I V$. Berlin: Springer-Verlag, 1980:235-40

\section{The diagnosis of toxoplasmosis}

The laboratory diagnosis of toxoplasmosis is based on identification or isolation of the organism in body fluids or tissues; measurement of antibodies; and finding cellular changes in lymph nodes. The diagnostic challenge lies in differentiating between a recently acquired infectionwhich is causing the patient's symptoms-and chronic infection, which is unrelated. This distinction may be difficult, because toxoplasma antibodies are frequently present in the general population, ${ }^{1}$ and they may persist for years at high titres. ${ }^{23}$ Furthermore, isolation of the organism from tissues may represent both old and recent infection (though its presence in body fluids indicates acute infection); nor are the clinical features of congenital or acquired toxoplasmosis unique to infection with this organism. ${ }^{4}$

Nevertheless, it is important to establish the presence of acute infection in order to start treatment at once in patients with severe or systemic symptoms or with chorioretinitis, in pregnant women and their infected infants, and in patients who are immunodeficient (the diagnosis of both reactivated and new infections in these patients is even more problematic and has recently been reviewed ${ }^{5}$ ). Treatment is not generally recommended for uncomplicated lymphoglandular toxoplasmosis, which is a self limiting illness. ${ }^{3}$ The diagnosis of acute infection is also important to minimise anxiety about possible malignancy in patients with unexplained lymphadenopathy.

The best serological means of diagnosing acute acquired toxoplasmosis is by assay of the specific IgM by an enzyme 
linked immunosorbent assay (ELISA) using antibody class capture. ${ }^{6}$ This procedure is now available in British reference laboratories and is more sensitive and specific than the hitherto widely used IgM immunofluorescent antibody test (IFAT). ${ }^{3}$ Single high titres of IgG antibody measured by the Sabin Feldman dye test and haemagglutination tests are rarely useful in identifying recent infections; theoretically rising titres are helpful but, in practice, because of timing of samples, rarely are so. ${ }^{2} \mathrm{~A}$ rapid, highly sensitive, and specific latex agglutination screening test is becoming increasingly available in general microbiological laboratories in order to detect IgG antibody in sera. Specimens giving a positive result may then be forwarded to the reference laboratories for full investigation. ${ }^{7}$ New methods of differentiating acute disease from chronic infection by detecting parasite antigens are being developed. ${ }^{89}$

Postnatally acquired clinical toxoplasmosis usually presents as an illness like glandular fever but in some patients the lymphadenopathy may be an isolated finding, unaccompanied by fever, and sometimes associated with lethargy and malaise. Such patients are likely to be investigated by biopsy of a lymph node as well as or instead of with microbiological tests-because of concern about neoplastic or granulomatous disease. The cellular changes of acute glandular toxoplasmosis are characteristic ${ }^{40-13}$ but not necessarily diagnostic, and probably histological diagnosis should always be supplemented by isolation studies or serology or both. ${ }^{11}$

Two recently published studies have confirmed earlier work showing that the cytopathological features of acute glandular toxoplasmosis closely parallel the histopathological changes, thereby adding fine needle aspiration biopsy to the diagnostic armament. ${ }^{1416} \mathrm{~A}$ toxoplasma cyst was identified in material from one patient. ${ }^{15}$ Although all patients in whom it was measured had high concentrations of specific IgM (IFAT), the usefulness of cytological tests in diagnosing recent infection was compared not with this serological investigation but, inexplicably, with that of the dye test titre.

In Britain the number of cases of lymphoglandular toxoplasmosis diagnosed by biopsy alone is unknown. Only $5 \%$ of such cases diagnosed serologically are reported to have the diagnosis confirmed histologically. ${ }^{17}$ Clearly the approach to the patient with unexplained lymphadenopathy should depend on the diagnostic probabilities suggested by the history and clinical examination. The possibility of a dual diagnosis of both lymphoma and toxoplasmosis has also to be considered. ${ }^{4}$ Many clinicians choose open biopsy to examine the architecture of the lymph nodes, although others will prefer needle biopsy, which will be appropriate in certain patients. Yet recent toxoplasmosis is still probably best diagnosed by serology-which is in any case necessary to confirm the histological findings.

The fear advanced in the United States that young adults with unexplained lymphadenopathy will need to be protected from "enthusiastic surgeons" because of this latest advance in the diagnosis of toxoplasmosis seems unlikely to be realised in Britain. ${ }^{18}$ Like many non-infectious diseases, toxoplasmosis is in danger of becoming another diagnosis made by a multitest process. A combination of clinical judgment and a close working relationship between the clinician and the laboratory should, however, still be able to spare the patient from too many investigations.

Senior Registrar,

SUSAN M HaLL

Public Health Laboratory Service Communicable Disease Surveillance Centre,

London NW9 5EQ
1 Fleck DG, Kwantes W. The laboratory diagnoses of toxoplasmosis. London: HMSO, 1980. (Public Health Laboratory Service Monograph Series 13 .

Welch PC, Masur H, Jones TC, Remington JS. Serologic diagnosis of acute lymphadenopathic

toxoplasmosis. $\mathcal{F}$ Infect Dis $1980 ; 142: 256-64$.
McCabe RE, Remington JS. The diagnosis and treatment of toxoplasmosis. Eur f Clin Microbiol

4 Remington JS. Toxoplasmosis in the adult. Bull NY Acad Med 1974;50:211-27

6 Payne RA. Isaac M. Francis JM. Enzyme-linked immunosorbent assay (EILISA 1984;i:605-6. A) using antibod class capture tor the detection of antitoxoplasma IgM. F Clin Pathol 1982;35:892-6. alfour AH, Fleck DG, Hughes HP, Sharp D. Comparative study of three tests (dye test, indirect haemagglutination test, latex agglutination test) for the detection of antibodies to Toxoplasma gondii in human sera. $\mathcal{F}$ Clin Pathol 1982;35:228-32.

8 Araujo FG, Remington JS. Antigenemia in recently acquired acute toxoplasmosis. $\mathcal{f}$ Infect $\mathrm{Dis}$ 1980;141:144-9.

Van Knapen F, Panggabaen DVM, Panggabean SO. Detection of toxoplasma antigen in tissues by means of enzyme-linked immunosorbent assay (ELISA). Am $\mathcal{J}$ Clin Pathol 1982;77:755-7. Saxen E, Saxen L, Gronroos P. Glandular toxoplasmosis: a report on 23 histologically diagnosed cases. Acta Pathologica et Microbiologica Scandinavica 1958;44:319-28.

Stansfeld AG. The histological diagnosis of toxoplasmic lymphadenitis. 3 Clin Pathol 1961;14:S65-73.

Gray GS, Kimball AC, $1972 ; 69: 349-58$.
Pathol

Pathol 1972;69:349-58.

Dorfman RF, Remington JS. Value of lymph node biopsy in the diagnosis of acute acquired toxoplasmosis. N Engl f Med 1973;289.878-81.

Christ ML, Feltes-Kennedy M. Fine needle aspiration cytology of toxoplasmic lymphadenitis.

Acta Cytol 1982;26:425-8.
Argyle JC, Schumann GB, Kjeldsberg CR, Athens JW. Identification of a toxoplasma cyst by fine needle aspiration. Am $\mathcal{F}$ Clin Pathol 1983;80:256-8.

Krug K. Die diagnostische und differential diagnostusche Wertigkeit zytologischer Befunde bie Lymphadenitis toxoplasmostica. Z Gesamte Inn Med 1977;32:615-8.

Bannister B. Toxoplasmosis 1976-80; review of laboratory reports to the Communicable Disease Surveillance Centre. foumal of Infection 1982;5:301-6.

$18 \mathrm{Kean}$ BH. Astronomic odds. Am $\mathcal{f}$ Clin Pathol 1983;81:272.

\section{Treatment of advanced carcinoma of the prostate}

About 6000 new patients will be found to have carcinoma of the prostate in Britain in 1984. Most of these will have metastatic disease at the time of presentation. In a consecutive series of 100 patients $32 \%$ of those with early tumours and $61 \%$ of those with advanced local disease had bony metastases.' Lymph node metastases are far more common than was previously thought and occur in up to $60 \%$ of patients without evidence of bony metastases. ${ }^{2}$ And the outlook is poor: in a collected series only $6 \%$ of untreated patients with metastatic disease survived five years. ${ }^{3}$

Effective endocrine treatment for prostatic cancer became available in 1941 after the reports by Huggins and Hodges. ${ }^{4}$ The initiai euphoria was soon tempered. Blanchot and Laporte drew attention to the cardiovascular complications associated with oestrogens, 5 and oestrogen related problems were borne out by large prospective trials in the United States. ${ }^{6}$ These studies showed that the mortality and morbidity associated with treatment with oestrogens were unacceptably high. ${ }^{7}$ It was apparent that the individual risk for cardiovascular side effects induced by oestrogens is enhanced in those with a previous disposition-for example, the elderly and those who have undergone recent surgery. ${ }^{8}$

Stilboestrol in a dose of $1 \mathrm{mg}$ three times a day appears to be as effective for treatment as higher doses, with correspondingly less (but still substantial) cardiovascular effects. Orchidectomy is used by some urologists as an alternative to oestrogens because cardiovascular problems do not occur, but it is unacceptable to many patients-and their urologists. Impotence and gynaecomastia are common with both treatments. A combination of orchidectomy and stilboestrol has been shown to be the best treatment for those with metastases at the time of presentation, though neither treatment has been convincingly shown to improve survival. ${ }^{39}$ One fifth of patients will not respond to this form of treatment, though it may be possible to predict those who will by measuring the nuclear androgen receptor content of the tumour. ${ }^{10}$ Of the responders, over half will relapse within two or three years, and this reactivated form of the disease is usually hormone resistant.

In short, refinements in conventional treatment are un- 